\title{
Performance Investigation of Air Velocity Effects on PV Modules under Controlled Conditions
}

\author{
Muzaffar Ali, ${ }^{1}$ Muhammad Hasan Iqbal, ${ }^{2}$ Nadeem Ahmed Sheikh, ${ }^{3}$ Hafiz M. Ali, ${ }^{1}$ \\ M. Shehryar Manzoor, ${ }^{1}$ Muhammad Mahabat Khan, ${ }^{3}$ and Khairul Fikri Tamrin ${ }^{4}$ \\ ${ }^{1}$ Mechanical Engineering Department, University of Engineering and Technology Taxila, Taxila, Pakistan \\ ${ }^{2}$ Mechanical Engineering Department, COMSATS Sahiwal, Sahiwal, Pakistan \\ ${ }^{3}$ Mechanical Engineering Department, Faculty of Engineering, HITEC University, Taxila, Pakistan \\ ${ }^{4}$ Department of Mechanical and Manufacturing Engineering, Faculty of Engineering, Universiti Malaysia Sarawak (UNIMAS), \\ 94300 Kota Samarahan, Sarawak, Malaysia
}

Correspondence should be addressed to Muzaffar Ali; muzaffar.ali@uettaxila.edu.pk

Received 26 May 2017; Accepted 6 August 2017; Published 12 December 2017

Academic Editor: Srinivas Devayajanam

Copyright (c) 2017 Muzaffar Ali et al. This is an open access article distributed under the Creative Commons Attribution License, which permits unrestricted use, distribution, and reproduction in any medium, provided the original work is properly cited.

\begin{abstract}
Junction temperature of PV modules is one of the key parameters on which the performance of PV modules depends. In the present work, an experimental investigation was carried out to analyze the effects of air velocity on the performance of two PV modules, that is, monocrystalline silicon and polycrystalline silicon under the controlled conditions of a wind tunnel in the presence of an artificial solar simulator. The parameters investigated include the surface temperature variation, power output, and efficiency of PV modules under varying air velocity from near zero (indoor lab. conditions) to $15 \mathrm{~m} / \mathrm{s}$. Additionally, the results were also determined at two different module angular positions: at $0^{\circ}$ angle, that is, parallel to air direction and at $10^{\circ}$ angle with the direction of coming air to consider the effects of tilt angles. Afterwards, the thermal analysis of the modules was performed using Ansys-Fluent in which junction temperature and heat flux of modules were determined by applying appropriate boundary conditions, such as air velocity, heat flux, and solar radiation. Finally, the numerical results are compared with the experiment in terms of junction temperatures of modules and good agreement was found. Additionally, the results showed that the maximum module temperature drops by $17.2^{\circ} \mathrm{C}$ and the module efficiency and power output increased from 10 to $12 \%$ with increasing air velocity.
\end{abstract}

\section{Introduction}

With the increasing demand of energy, attention of researchers is titillating towards the renewable energy sector. PV cells have gained much attention in past couple of years. The total PV capacity of all major countries increased from about $40 \mathrm{GW}$ to $100 \mathrm{GW}$ during 2010-2012 [1]. With the rising demand of energy and environmental effects of other energy sources, an efficient utilization of solar energy is considered to be the best way for power generation $[2,3]$.

Although PV system allows direct electrification of solar energy, however, it faces severe limitations when the surface temperature of the module increases. Generally, high solar irradiance comes with higher ambient temperatures especially in climatic zones such as Pakistan. For such zones, energy utilization efficiency of PV systems can be improved through different methods for instances: multijunction cells [4], optical frequency shifting [5], multiple generation cells [6], hot carrier cells [7], and concentration photovoltaic system [8]. However, such methods have not been yet commercialized because of their complexity and high cost. Therefore, cheap and simple methods to improve the efficiency of PV systems become the basic need of this technology especially in those areas where high temperatures are experienced.

The standard test conditions of typical photovoltaic modules consist of global irradiance of $1000 \mathrm{~W} / \mathrm{m}^{2}$, module temperature of $25^{\circ} \mathrm{C}$, and air mass 1.5 (according to IEC $61215 /$ IEC 61646 tests) in which certified measurement was performed by TÜV immissionsschutz und Energiesysteme GmbH (Cologne, Germany) [9]. However, these values may 
not comply with the measurements in actual operating conditions because of variations in several environmental parameters [10]. Therefore, the predicted module performance deviates under real climate conditions. PV panels absorb around $80 \%$ of the incident solar irradiation but their maximum theoretical conversion efficiency is not more than $30 \%$ due to various losses $[11,12]$. A major cause of these losses is the heat generation during absorption of photons that results in high junction temperature causing thermalization that decreases output power and efficiency of PV cells. In order to gain the maximum efficiency from PV cells, their junction temperature is required to be kept low, that is, around $25^{\circ} \mathrm{C}$.

Several studies have been conducted to study the dependence of module performance on its junction temperature. In a reported work, it was investigated that with the increase in the junction temperature, the reverse saturation current increases which causes a decrease in the open circuit voltage $\left(V_{\mathrm{oc}}\right)$; thus, the efficiency of modules decreases [13].

In another similar study, it was observed that the efficiency of PV modules depends upon many environmental parameters out of which temperature plays a vital role on the performance of modules. The investigation carried out at high irradiance showed that the module working temperature will be high resulting in lower efficiency of modules [14]. In one of the research work, an active cooling system for solar panels was proposed and investigated showing that when there is no active cooling, the efficiency of panels was about $9 \%$, and with active cooling, the temperature of the panel decreases appreciably with their efficiency increased up to $12-13 \%$ [15].

In a study, the effects of other environmental variables such as dust, humidity, and air velocity on the efficiency of solar panels were investigated. Accumulation of dust on panel surface and increase in relative humidity causes a decrease in the efficiency of panels. When air flows on the surface of panels it is expected to blow away dust particles and remove the heat from the panel surface, primarily through convection. This decreases the temperature of panels and also results in the decrease of local relative humidity, and the overall result is increased efficiency of the panels [16]. To reduce the cell temperature, a research was carried out to investigate the effects of microchannel cooling of PV cells on their efficiency. This approach resulted in a $14 \%$ increase in power output with a temperature drop of up to $15^{\circ} \mathrm{C}$. This temperature drop was caused by water flow in microchannels on the back surface of cells at the rate of 3 LPM [17].

The body of cited literature suggests that a number of studies have been carried out to study the influence of various external parameters and mechanisms on performance of PV modules. From the commercial point of view, wind blowing over the installed PV modules whether on small scale or large scale provides a simple and economical solution. However, such solution requires investigation and quantification in a controlled situation. Until now no appropriate quantificational assessment on the airflow over PV module has not been studied in detail. In order to ascertain the influence of airflow, in a parametric fashion, a controlled experimental setup is required for testing. Here, a controlled set of conditions is established by placing the PV panel in a wind tunnel with exact quantification of airflow and its direction. The real-time performance of the PV module is assessed in presence of an artificial solar simulator. This experiment is designed to quantify the influence of air velocity on the performance of PV module. As the solar panels are installed at a specific tilt, the effect of tilt angle is also studied so that the results can be utilized, with confidence, while designing cooling mechanisms for PV modules.

\section{Methodology}

Maximum power of the PV module is the product of maximum current and maximum voltage as determined by

$$
P_{\max }=E_{\max } I_{\max } \text {. }
$$

Module efficiency is determined by

$$
\eta_{\mathrm{m}}=\frac{P_{\max }}{I_{\mathrm{rr}} A},
$$

where $I_{\mathrm{rr}}$ is the amount of solar radiation in $\mathrm{W} / \mathrm{m}^{2}$ and $A$ is the active area of cells on which the radiation is focused. The heat flux on the surface of cell is measured by

$$
Q=h A\left(T_{\mathrm{s}}-T_{\mathrm{a}}\right),
$$

where $h$ is the convective heat transfer coefficient, $T_{\mathrm{s}}$ is the junction temperature of panel, and $T_{\mathrm{a}}$ is the temperature of incoming air. The relationship as expressed through 4 is used to determine the convective heat transfer coefficient, primarily for laminar flow [18].

$$
h=3.83 V^{0.5} L^{-0.5} \text {, }
$$

where $V$ is the upstream air velocity and $L$ is the characteristic length of the module.

2.1. Experimental Setup and Procedure. Experiments were conducted to estimate the behavior of different types of PV modules under controlled conditions. PV modules were placed on a moveable stand placed inside the wind tunnel test section (dimension: $0.13 \times 0.093 \mathrm{ft}^{2}$ ) made with Perspex glass. There were four K-type thermocouples attached to the backside of PV module. The test box was mounted with a low subsonic wind tunnel (model number HM 170) with a maximum airspeed of $25 \mathrm{~m} / \mathrm{s}$. The platform was placed at the center of the wind tunnel test section. The test section was placed under an artificial solar simulator (model number TRM-PD) having a maximum electrical power of $3 \mathrm{~kW}$. The platform with PV cells was placed right beneath the solar simulator so that maximum radiations directly fall on the module. The actual experimental setup is shown in Figure 1. The rated specifications of the PV modules (manufactured by Polysun Energy) are given in Table 1.

Air velocity inside the wind tunnel was controlled using a calibrated inclined manometer. The intensity of incident 


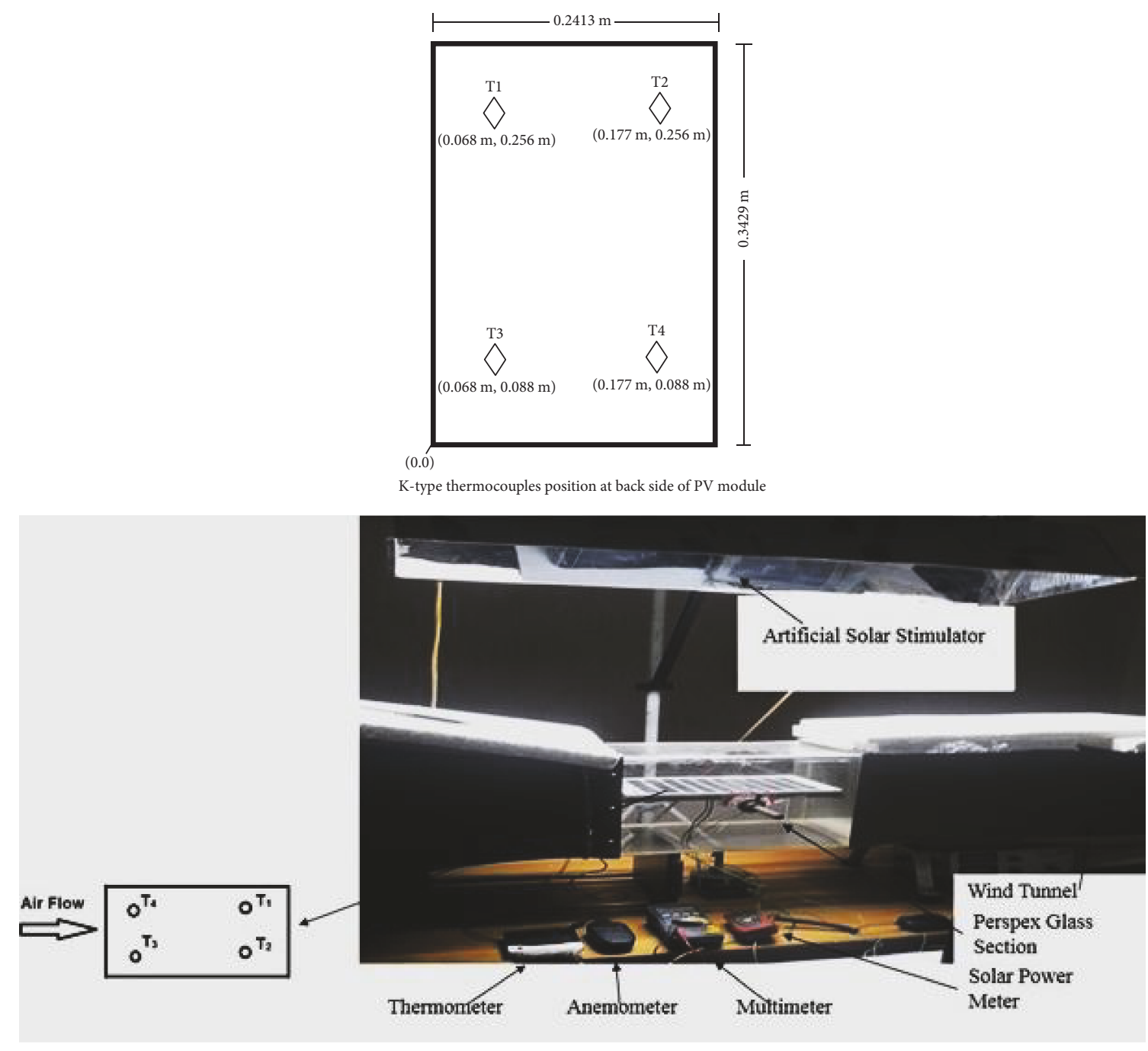

FIGURE 1: Schematic description of placement of thermocouples on PV module and the actual experimental setup in the wind tunnel.

TABLE 1: Module specifications.

\begin{tabular}{lcc}
\hline Module design parameters & $\mathrm{c}-\mathrm{Si}$ & $\mathrm{p}-\mathrm{Si}$ \\
\hline Module dimensions $(\mathrm{mm} \times \mathrm{mm})$ & $342.9 \times 241.3$ & $342.9 \times 241.3$ \\
Module area $\left(\mathrm{m}^{2}\right)$ & 0.0816 & 0.0816 \\
Maximum power, $P_{\max }(W)$ & $10 \mathrm{~W} \pm 3 \%$ & $10 \mathrm{~W} \pm 3 \%$ \\
Maximum current, $I_{\max }(A)$ & 0.56 & 0.57 \\
Maximum voltage, $E_{\max }(V)$ & 18 & 17.5 \\
Short circuit current, $I_{\mathrm{sc}}(A)$ & 0.64 & 0.66 \\
Open circuit voltage, $V_{\mathrm{oc}}(V)$ & 21.6 & 21.5 \\
\hline
\end{tabular}

radiations was measured through solar power meter (model number (Amprobe Solar-100)). For temperature measurement on the surface of the PV panel, four K-type thermocouples were installed on the backside of panels with the help of a heat-conducting adhesive. The temperature of panel surface with air approaching and leaving the module was measured through these thermocouple probes.
Initial performance of the PV panels was noted at zero wind conditions (static wind tunnel fan) under the solar simulator only. The temperature and relevant parameters of the modules were recorded until the average surface temperature of the panel reached $40^{\circ} \mathrm{C}$. Afterwards, similar measurements were made at different airflow velocities at fixed incident radiations. A similar procedure was repeated for PV panels tilted at an angle of $10^{\circ}$ with the horizontal. The set of measurements include the incident intensity of radiation, temperature of module at four points, and current and voltage produced by the PV panel. The measurements were made for sufficiently long durations so that time averaged steady values are noted and these values are then used for further calculations and comparisons. The velocity of the wind was increased incrementally and the same procedure was adopted. The temperatures of the module were measured only once stable condition is achieved at a set wind speed. The same set of experiments was repeated for both mono- and polycrystalline modules at both $0^{\circ}$ and $10^{\circ}$ tilt angles. The purpose of introducing the tilt angle was to analyze the 
TABLE 2: Calculation of Reynolds number.

\begin{tabular}{lc}
\hline Velocity $(\mathrm{m} / \mathrm{s})$ & Reynolds number \\
\hline 5 & $116,405.8$ \\
6 & 139,687 \\
7 & $162,968.1$ \\
8 & $186,249.3$ \\
9 & $209,530.5$ \\
10 & $232,811.6$ \\
11 & $256,092.8$ \\
12 & 279,374 \\
13 & $302,655.1$ \\
14 & $325,936.3$ \\
15 & $349,217.4$ \\
\hline
\end{tabular}

effects of airflow over the actual installation configuration of modules in tilted mode.

2.2. Numerical Analysis. The process of heat transfers from the surface of modules due to varying flow speeds is analyzed using numerical simulations. As the experiments were conducted under controlled conditions, the rate of heat removal from the surface of the module can be simulated and results can be compared with experimental measurements. Using a commercial CFD code (Fluent), flow over a 2D flat plate, mimicking the module, is simulated at varying airspeeds. It was noted that under zero wind conditions, the maximum temperature of the modules was raised to $40^{\circ} \mathrm{C}$ due to radiations of the solar simulator and power generation of panels. Under zero wind speed, heat flux generated by the module was calculated using the surface temperature measurements and is used as a boundary condition for the simulations. Under constant influx of radiations, it is assumed that the heat flux generated by the panel does not change significantly. However, the surface temperatures of the module are expected to vary at varying flow velocities and numerical simulations are used to predict the surface temperature variations.

For flow over a flat plate, transition from laminar to turbulent is usually taken to occur at the critical Reynolds number. The value of the critical Reynolds number for a flat plate may vary from $5 \times 10^{5}$ to $3 \times 10^{6}$, depending on the surface roughness and the turbulence level of the free stream [19]. Maximum Reynolds number for the study was calculated $3.5 \times 10^{5}$ as given in Table 2 where density is $1.225 \mathrm{kgm}^{-3}$, viscosity is $0.00001789 \mathrm{Nsm}^{-2}$, and characteristic length $L$ is $0.34 \mathrm{~m}$, so the flow over the flat module was assumed to remain laminar.

Temperature of the incoming airflow was measured during experiments and kept at $T_{\text {air }}=293 \mathrm{~K}$ for all simulations. The flow at the inlet was assumed to be uniform with its magnitude ranging from 5 to $15 \mathrm{~m} / \mathrm{s}$. The simulated geometry and relevant boundaries are indicated in Figure 2.

2.2.1. Governing Equations and Boundary Conditions. The simulation involves solving balances of mass, momentum, and energy with relevant boundary conditions. The set of equations for incompressible, steady laminar flow of fluid with constant physicothermal properties are as follows:

Continuity equation

$$
\frac{\partial U}{\partial X}+\frac{\partial V}{\partial Y}=0
$$

X-momentum equation

$\frac{\partial(U U)}{\partial X}+\frac{\partial(V U)}{\partial Y}=-\frac{(\partial p / \partial X)+\left(\partial^{2} U / \partial X^{2}\right)+\left(\partial^{2} U / \partial Y^{2}\right)}{\operatorname{Re}}$,

Y-momentum equation

$\frac{\partial(U V)}{\partial X}+\frac{\partial(V V)}{\partial Y}=-\frac{(\partial p / \partial Y)+\left(\partial^{2} V / \partial X^{2}\right)+\left(\partial^{2} V / \partial Y^{2}\right)}{\operatorname{Re}}$,

Thermal energy equation

$$
\frac{\partial(U \theta)}{\partial X}+\frac{\partial V \theta}{\partial Y}=\frac{\left(\partial^{2} \theta / \partial X^{2}\right)+\left(\partial^{2} \theta / \partial Y^{2}\right)}{\operatorname{RePr}},
$$

where Reynolds and Prandtl numbers are defined as

$$
\begin{aligned}
& \operatorname{Re}=\frac{(L U \rho)}{\mu}, \\
& \operatorname{Pr}=\frac{\left(\mu c_{p}\right)}{k} .
\end{aligned}
$$

No slip condition was used over the cylinder surface with uniform heat flux thermal boundary condition.

For uniform heat flux, the nondimensional temperature is given as $\theta=T-T \infty /\left(q_{\mathrm{w}} D / k\right) \cdot q_{w}$ is specified heat flux, $D$ is characteristic length, and $k$ is thermal conductivity.

2.2.2. Numerical Details. For the problem in consideration, computational grid was generated using Gambit software and the numerical calculations were accomplished using a computational fluid dynamics (CFD) solver FLUENT (14.0). A multiblock-structured grid was used. Figure 3 shows the grid employed for the simulations and results reported in this paper.

In order to establish grid independence of results, a detailed study was conducted. Computations were performed on 3 different grids in order to get domain-independent results. The total number of grid points was varied to select the grid that generates accurate results with a minimum number of nodes to save computation time. The number of elements in grid 3 was more than grid 2 and grid 1 but the results obtained from executing grid 3 were more accurate and precise than the results attained from grid 1 and grid 2 as shown in Table 3 . Therefore, grid 3 was selected with a total of 38,230 cells. 


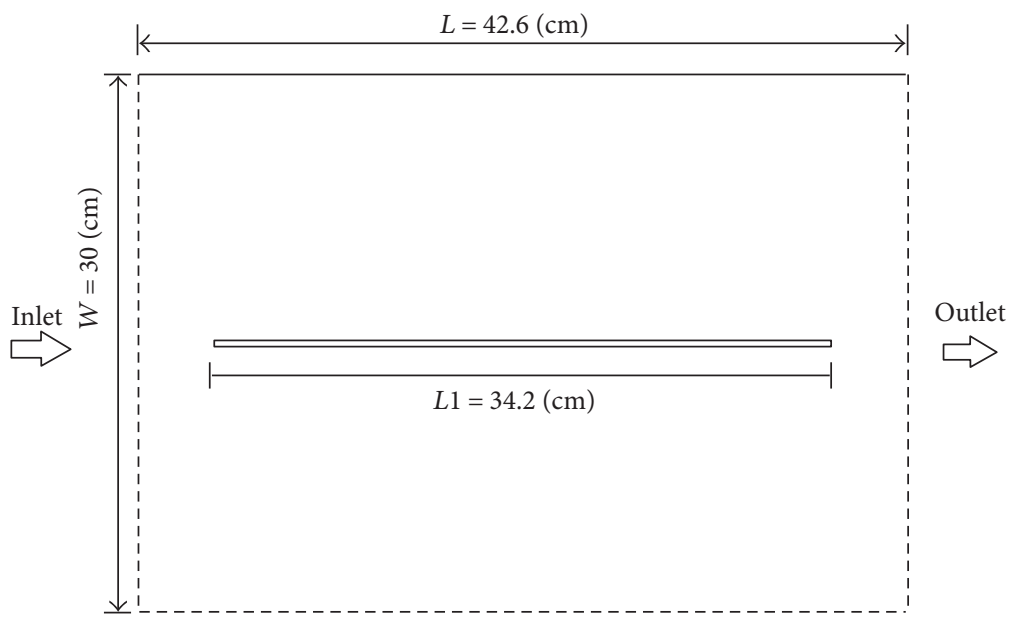

FiguRE 2: Schematic diagram of unconfined flow on module.

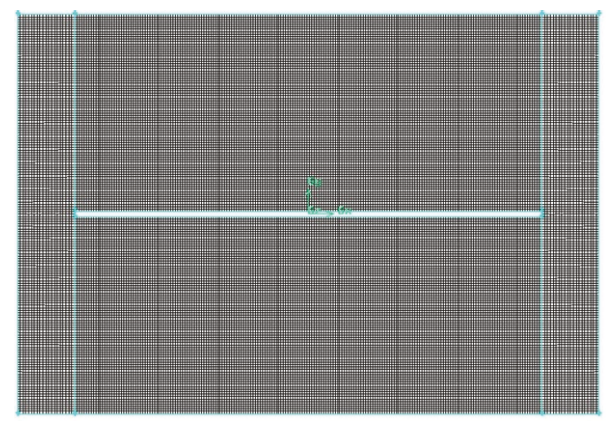

FIgure 3: Grid structure corresponding to G3 (Table 3) for the simulation.

\section{Results and Discussion}

After comprehensive numerical and experimental analysis, results are presented in terms of module power, temperature, and efficiency.

\subsection{Module Temperature Analysis}

3.1.1. Experimental Variation of the Surface Temperature of the PV Module with the Airflow Velocity. Figure 4 shows experimental results of temperature for monocrystalline and polycrystalline modules. Figures 4(a) and 4(b) show the temperature results obtained from monocrystalline module at positions $0^{\circ}$ and $10^{\circ}$, respectively, while Figures 4(c) and 4(d) show the trends obtained from the polycrystalline module. The temperatures at four different points on the module are represented. Additionally, the average temperature of module is also shown. It can be observed that temperatures labeled as $\mathrm{T} 1$ and $\mathrm{T} 2$ are slightly high compared to temperatures T3 and T4. This is due to the fact that air gets heated along its flow path from point $\mathrm{T} 3$ and $\mathrm{T} 4$ to point $\mathrm{T} 1$ and $\mathrm{T} 2$. In the presence of a solar simulator, the temperature readings were recorded with an average temperature of module reaching $40^{\circ} \mathrm{C}$ (maximum temperature considered in the current study). At higher velocities, the temperature of the monocrystalline module decreases up to $16.8^{\circ} \mathrm{C}$ compared to zero velocity measurement. Whereas the drop in temperature for polycrystalline module was up to $17.2^{\circ} \mathrm{C}$ compared to zero velocity measurement as shown in Figure 4 . It can be concluded that there was a significant drop in temperature when the airflow velocity was at $5 \mathrm{~m} / \mathrm{s}$. However, at velocities greater than $15 \mathrm{~m} / \mathrm{s}$, the temperature depression was not significant.

3.1.2. Calculation of the Temperature Variation of the $P V$ Cells with Air Velocity. Figures 5(a)-5(d) show the temperature results along the length of monocrystalline and polycrystalline PV modules at velocities of $5,8,12$, and $15 \mathrm{~m} / \mathrm{s}$. The results show that the temperature of panel increased along the length of the panel; this is due to the fact that air gets heated up as it flows over the panel along the length and heat transfer rate decreases due to decrease in temperature difference.

A comparison of numerical simulations with experimental results is represented in Figure 6. The simulation results near the leading tip of the module are compared with the average temperature of points (T3, T4) as shown in Figures 6(a), 6(c), 6(e), and 6(f). While the simulated results at the trailing end of module were compared with the average temperature of points (T1, T2) as shown in Figures 6(b), 6(d), $6(\mathrm{f})$, and $6(\mathrm{~h})$. The comparison indicates that the results of temperatures obtained experimentally are in good agreement with the numerically achieved results as the trend of both lines is almost the same and the difference between the results was found to be around $2^{\circ} \mathrm{C}$, mainly towards the leading tip. The expected reason for the deviation is flow transition taking place inside the wind tunnel, which could have disturbed the leading edge flow patterns. Also, the leading point of the boundary layer has high local heat transfer coefficient, and deviation of around $10 \%$ at the leading edge is quite admissible. The numerical simulations showed good agreement with experimental findings, especially after the leading edge as shown in Figures 6(b), 6(d), 6(f), and 6(h). This comparison shows a reliable means to directly estimate 
TABle 3: Details of meshes tested in grid independence.

\begin{tabular}{lccccccc}
\hline Grid & Nodes & $\begin{array}{c}\text { Number } \\
\text { of cells }\end{array}$ & $\begin{array}{c}\text { Domain size } \\
(\mathrm{cm})\end{array}$ & $\begin{array}{c}\text { Step size } \\
\Delta t(\mathrm{~s})\end{array}$ & $\begin{array}{c}\text { Experimental temperature of } \\
\text { module }(\mathrm{K})\end{array}$ & $\begin{array}{c}\text { Fluent temperature of } \\
\text { module }(\mathrm{K})\end{array}$ & $\begin{array}{c}\text { Difference in } \\
\text { temperature }(\mathrm{K})\end{array}$ \\
\hline G1 & 25,002 & 24,272 & $30 \times 42.6$ & 0.0008 & 297.4 & 293.9 & 3.5 \\
G2 & 36,492 & 35,600 & $30 \times 42.6$ & 0.0008 & 297.4 & 295.4 & 2 \\
G3 & 39,246 & 38,320 & $30 \times 42.6$ & 0.0008 & 297.4 & 296.1 & 1.3 \\
\hline
\end{tabular}
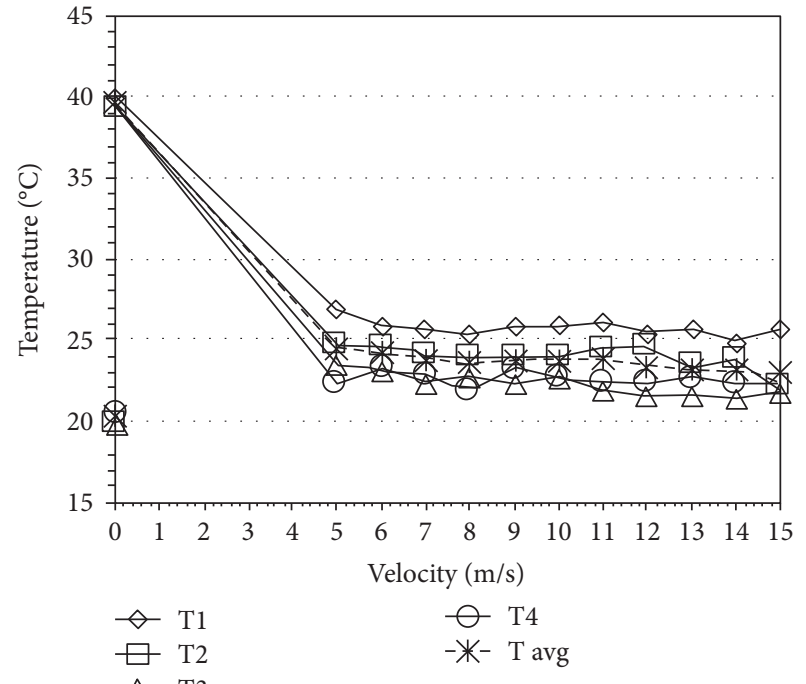

(a)

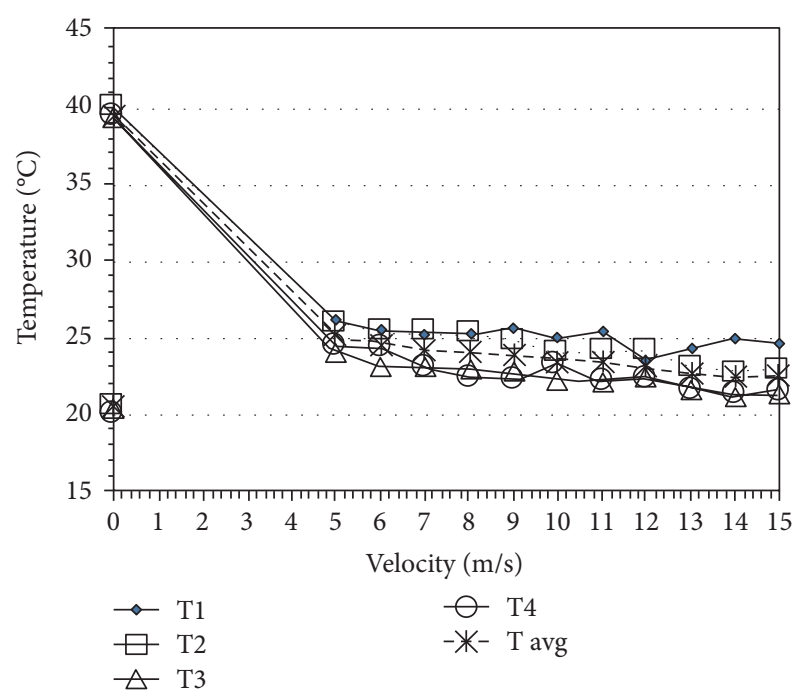

(c)

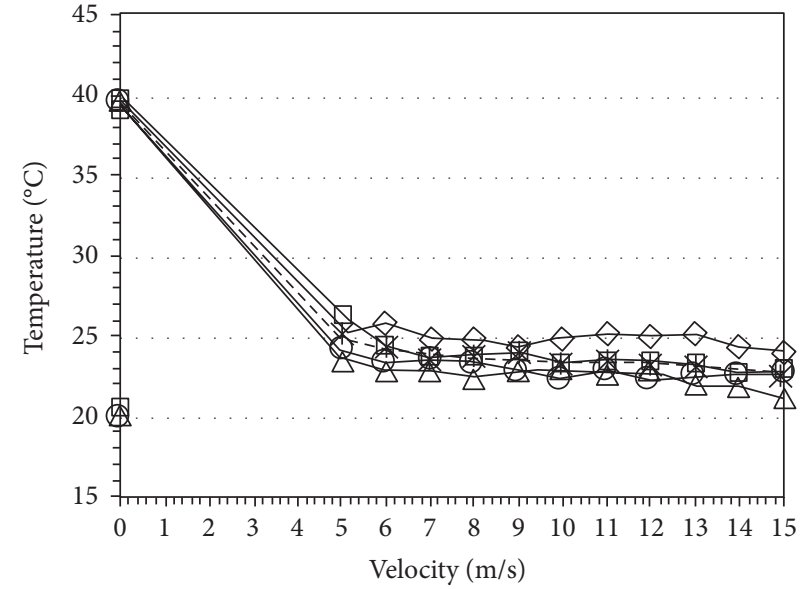

$\square \mathrm{T} 2 \quad-$ * $-\mathrm{T}$ avg

$\triangle \mathrm{T} 3$

(b)

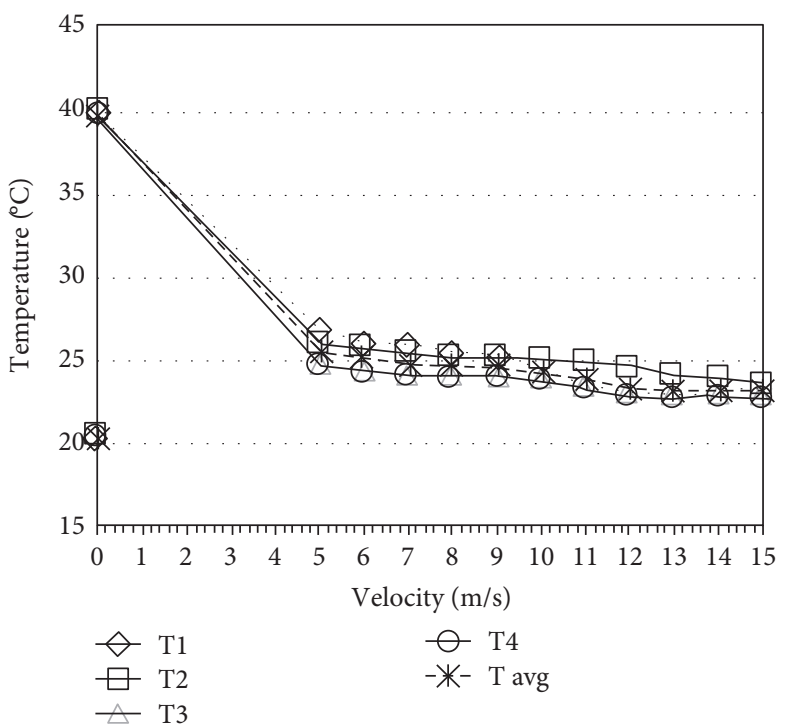

(d)

FIgURE 4: Variation of temperature with velocity. (a) Monocrystalline at $0^{\circ}$, (b) monocrystalline at $10^{\circ}$, (c) polycrystalline at $0^{\circ}$, and (d) polycrystalline at $10^{\circ}$.

surface temperatures over the complete surface of the module. Furthermore, the numerical methods can be directly employed in real-time scenarios and configurations.

3.2. Variation of Module Power and Efficiency with Air Velocity. Figure 7 shows the effect of velocities on the power of modules. Initially, at high temperature, the module power was recorded low when the air velocity was almost negligible, while at higher velocities, the module power increases due to the decrease in temperature of module. Maximum power achieved was $7.5 \mathrm{~W}$ for monocrystalline module and $4.8 \mathrm{~W}$ for polycrystalline module under considered conditions. 


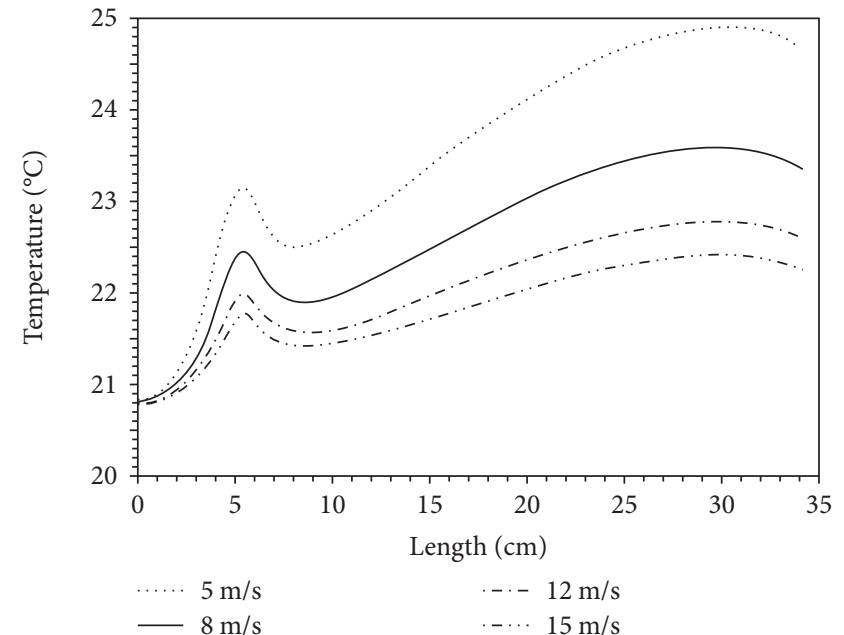

(a)

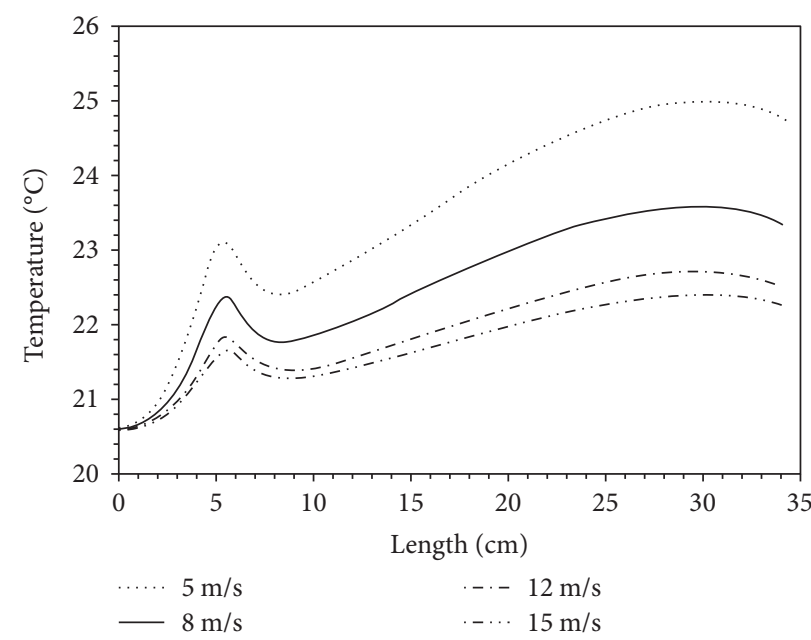

(c)

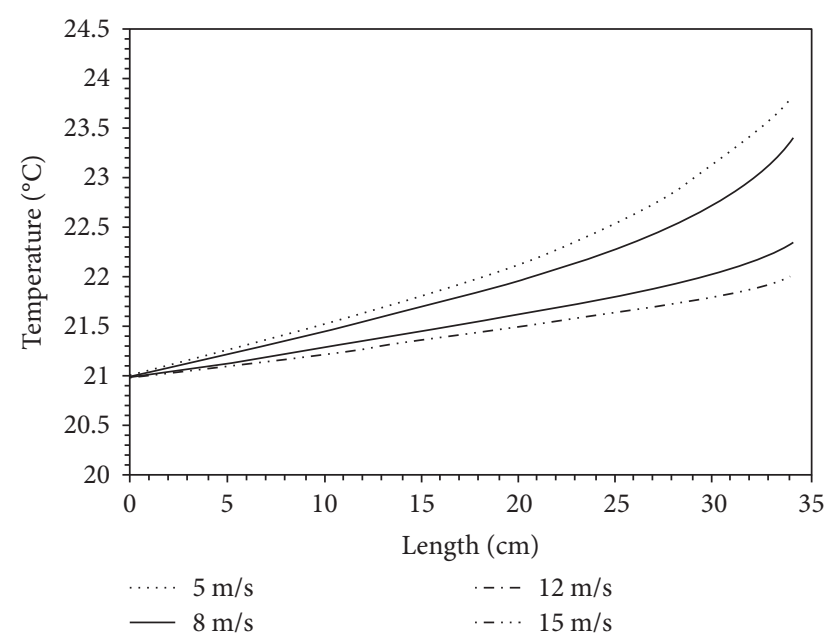

(b)

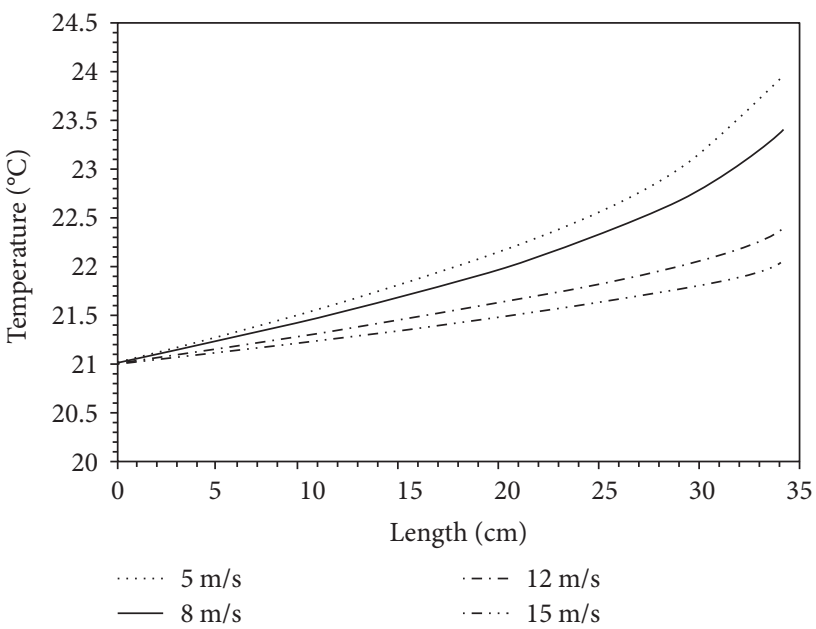

(d)

FIgURE 5: PV module surface temperature along length. (a) Monocrystalline at $0^{\circ}$, (b) monocrystalline at $10^{\circ}$, (c) polycrystalline at $0^{\circ}$, and (d) polycrystalline at $10^{\circ}$.

Figures $7(\mathrm{a})$ and $7(\mathrm{~b})$ show the results for monocrystalline and polycrystalline modules correspondingly. The variation in angles of modules from $0^{\circ}$ to $10^{\circ}$ results in additional air contact with modules, owing to which further decrease in temperature and increase in power are observed.

Figure 8 indicates that the efficiency of photovoltaic modules followed exactly the same trend as shown in Figure 7. The efficiency of modules is directly proportional to the power. The increase in power and efficiency of monocrystalline and polycrystalline modules at position $0^{\circ}$ with the airflow was found to be $10-15 \%$ and $5-10 \%$, respectively, while in the case of tilt angle of $10^{\circ}$ with the incoming airflow, increase in performance parameters for both modules is found to be $11-18 \%$ and $8-12 \%$, respectively, at considered velocity range. Thus, it can be concluded that the effects of airflow on the modules' power and efficiency at a tilt angle of $10^{\circ}$ are better than at $0^{\circ}$. Furthermore, from these results, it be can be also concluded that the effects of airflow on monocrystalline module are significant compared to the polycrystalline module under the same conditions.

\section{Conclusions and Future Work}

The effect of blowing wind on photovoltaic modules was studied experimentally and results are compared with numerical simulations. It is observed that the effect of wind on the temperature of PV module is significant, which results in increase of power and efficiency of modules. Results showed that at moderate velocity of air, significant change in module temperature is observed. Further higher velocities of air do not necessarily increase the advantage. At air velocity range of 5 to $15 \mathrm{~m} / \mathrm{s}$ up to $42 \%$, decrease in average temperature of monocrystalline module was observed whereas the drop in temperature for polycrystalline module was up to $43 \%$. This leads to increase in power and efficiency of monocrystalline and polycrystalline modules. Moreover, the influence of inclination angle is also significant. At tilt 


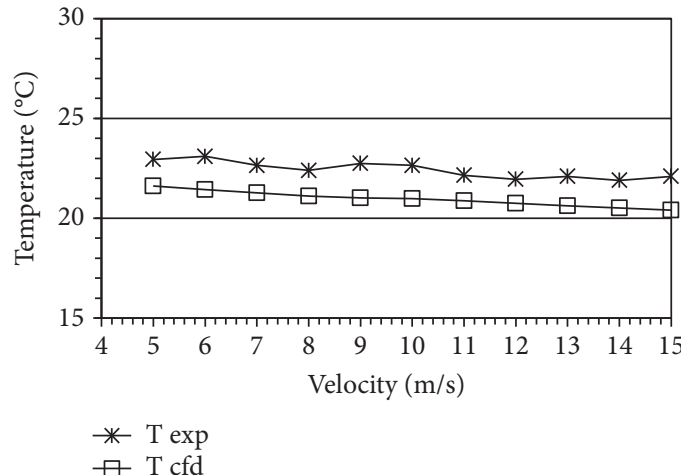

(a)

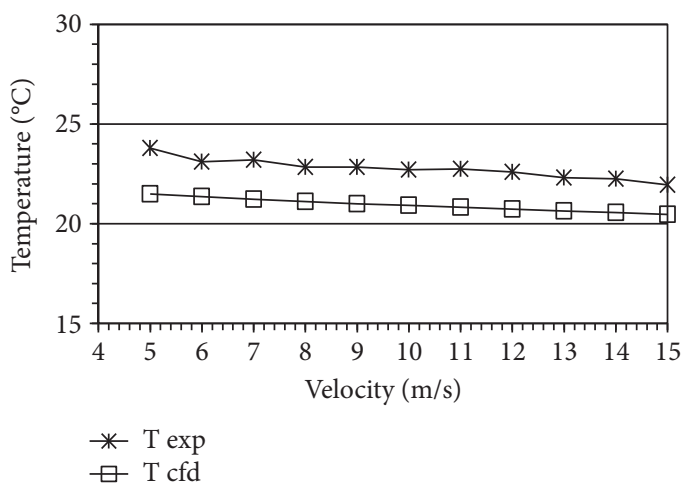

(c)

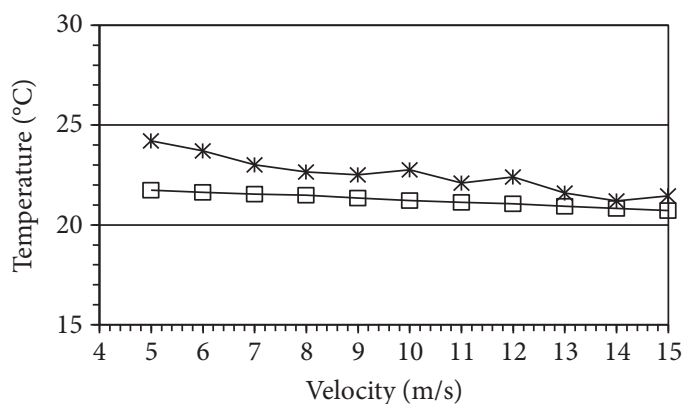

* T exp

Ð T cfd

(e)

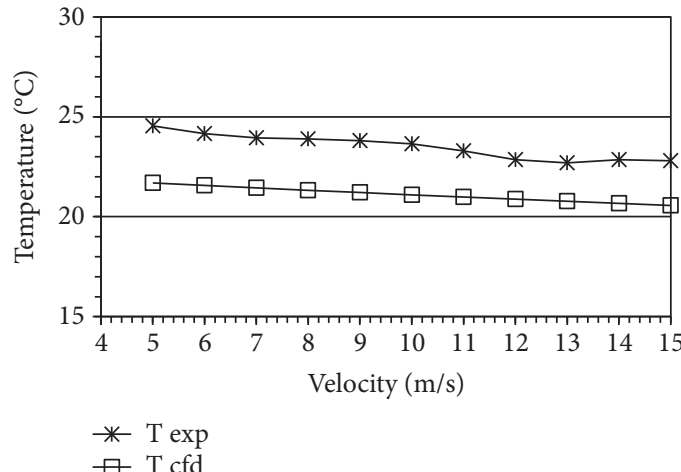

(g)

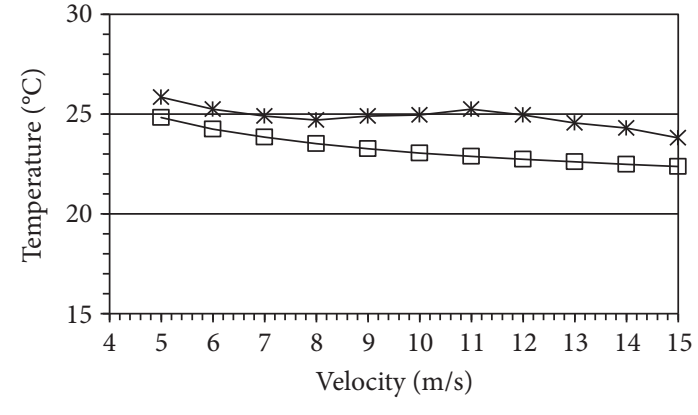

* T exp

$\square$ T cfd

(b)

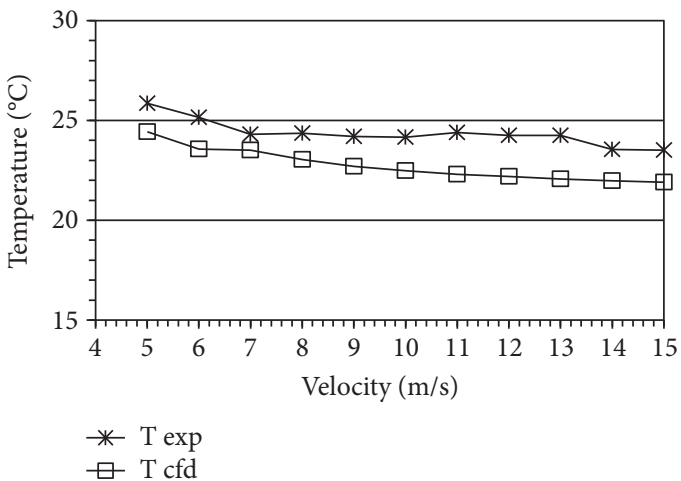

(d)

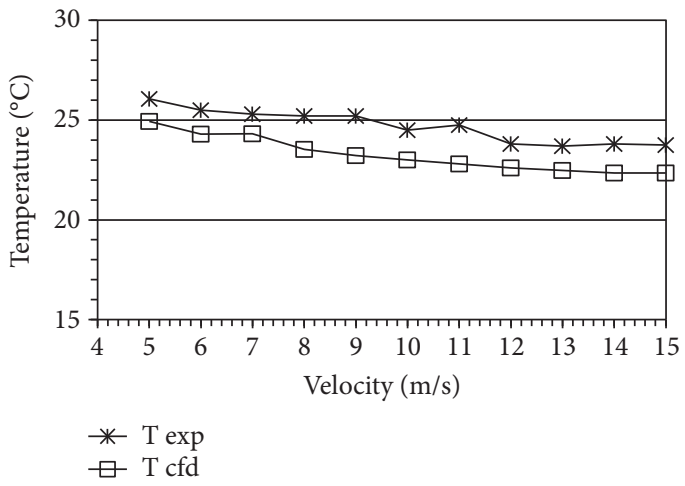

(f)

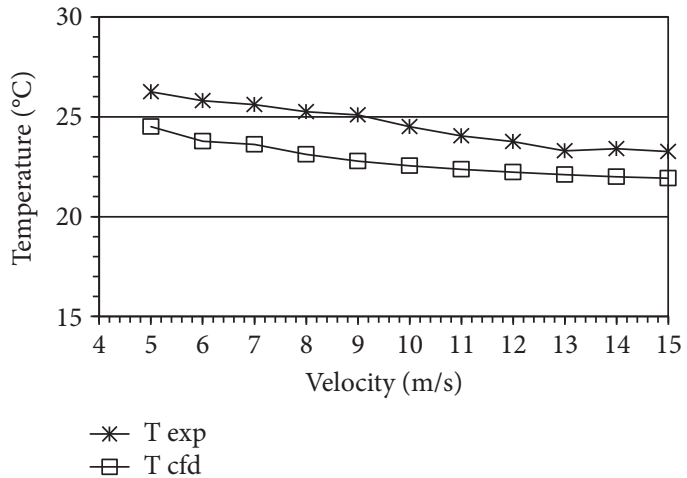

(h)

FIgure 6: Comparison between experimental and CFD temperature results. (a) Monocrystalline at $0^{\circ}$ initial point, (b) monocrystalline at $0^{\circ}$ final point, (c) monocrystalline at $10^{\circ}$ initial point, (d) monocrystalline at $10^{\circ}$ final point, (e) polycrystalline at $0^{\circ}$ initial point, (f) polycrystalline at $0^{\circ}$ final point, (g) polycrystalline at $10^{\circ}$ initial point, and (h) polycrystalline at $10^{\circ}$ final point. 


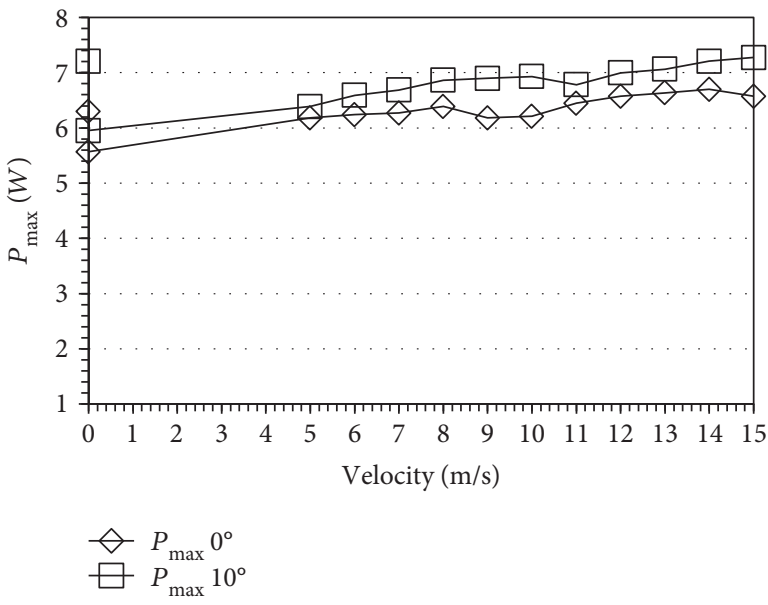

(a)

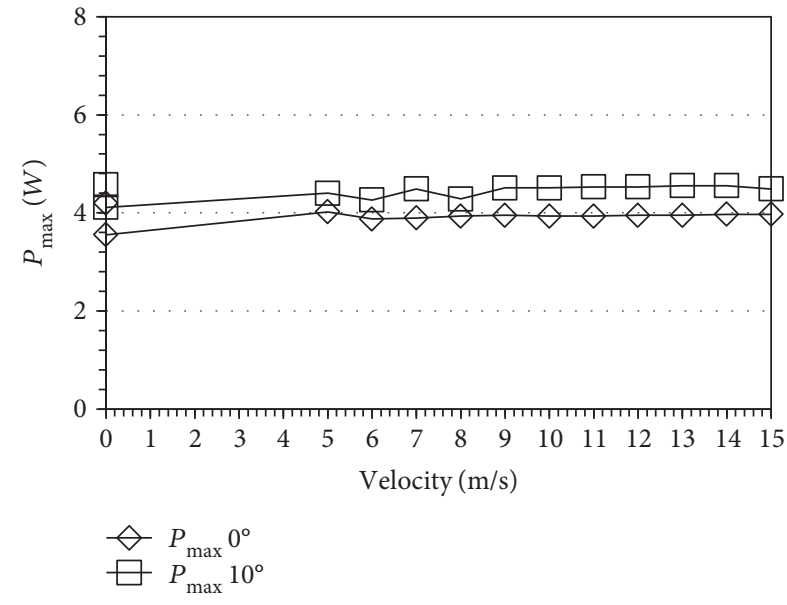

(b)

Figure 7: Modules power at different velocities. (a) Monocrystalline and (b) polycrystalline.

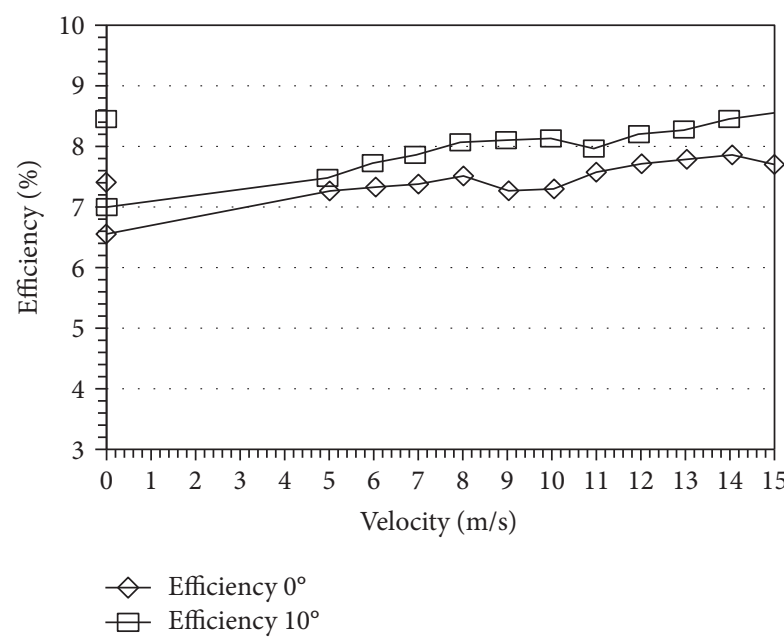

(a)

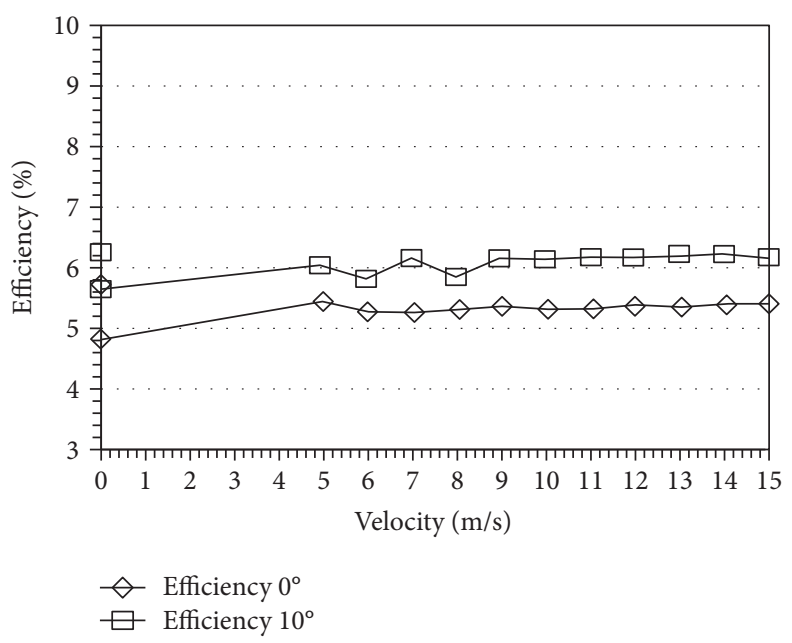

(b)

FIgURE 8: Modules efficiency at different velocities. (a) Monocrystalline and (b) polycrystalline.

angle of $0^{\circ}$ with the airflow, it was found that the efficiency of monocrystalline module increases from 10 to $15 \%$ while for polycrystalline module the increase was from 5 to $10 \%$. In case of tilt angle of $10^{\circ}$ with the incoming airflow, increase in performance parameters for both modules are found to be 11 to $18 \%$ and 8 to $12 \%$, respectively.

\section{Nomenclature}

A: Active area of cells $\left[\mathrm{m}^{2}\right]$

C-Si: Monocrystalline silicon module

$h$ : convective heat transfer coefficient $\left[\mathrm{W} / \mathrm{m}^{2} \mathrm{~K}\right]$

I: $\quad$ Current $[\mathrm{A}]$

$I_{\mathrm{rr}} \quad$ Solar irradiance $\left[\mathrm{W} / \mathrm{m}^{2}\right]$

$L: \quad$ Length of panel $[\mathrm{m}]$

P-Si: Polycrystalline silicon module

$P: \quad$ Power [W]

Q: $\quad$ Heat flux $\left[\mathrm{W} / \mathrm{m}^{2}\right]$
STC: Standard testing condition

T: $\quad$ Temperature $\left[{ }^{\circ} \mathrm{C}\right]$

E: $\quad$ Voltage $[\mathrm{V}]$

Re: Reynolds number

Pr: Prandtl number

$U: \quad$ Velocity along $x$-axis $[\mathrm{m} / \mathrm{s}]$

$V: \quad$ Velocity along $y$-axis $[\mathrm{m} / \mathrm{s}]$

$n_{s:} \quad$ Normal unit direction vector

$q_{w}$ : Specified heat flux

$D$ : $\quad$ Characteristic length

K: Thermal conductivity.

\section{Greek Symbols}

$\mu: \quad$ Dynamic viscosity $\left[\mathrm{kg} \cdot \mathrm{m}^{-1} \cdot \mathrm{s}^{-1}\right]$

$\eta_{\mathrm{m}}:$ Module efficiency (\%)

$\theta$ : Nondimensional temperature

$\rho: \quad$ Density $\left[\mathrm{kg} / \mathrm{m}^{3}\right]$. 


\author{
Subscripts \\ a: $\quad$ Air \\ Max: maximum \\ Mea: Measured \\ sc: $\quad$ Short circuit \\ s: $\quad$ Surface of module \\ oc: Open circuit.
}

\section{Conflicts of Interest}

The authors declare that they have no conflicts of interest.

\section{Acknowledgments}

This work was supported by Mechanical Engineering Department of University of Engineering and Technology Taxila, Pakistan, which is gratefully acknowledged.

\section{References}

[1] N. Stephen, "Trends in photovoltaic applications," in International Energy Agency Report, IEA-PVPS T1-23, 2013.

[2] N. S. Sariciftci, Organic Photovoltaics Mechanisms Materials and Devices, CRC Press, Boca Raton, 2005.

[3] R. H. Bube, Photovoltaic Materials, Imperial College Press, London, 1998.

[4] R. J. Kaplar, D. Kwon, S. A. Ringel et al., "Deep levels in p-and n-type In $\mathrm{Ga}$ As $\mathrm{N}$ for high-efficiency multi-junction III-V solar cells," Solar Energy Materials and Solar Cells, vol. 69, no. 1, pp. 85-91, 2001.

[5] T. Trupke, M. A. Green, and P. Würfel, "Improving solar cell efficiencies by down-conversion of high energy photons," Journal of Applied Physics, vol. 92, no. 3, pp. 1668-1674, 2002.

[6] R. D. Schaller and V. I. Klimov, "High efficiency carrier multiplication in PbSe nanocrystals: implications for solar energy conversion," Journal of Applied Physics, vol. 92, no. 18, article 186601, 2004.

[7] R. T. Ross and A. J. Nozik, "Efficiency of hot-carrier solarenergy converters," Journal of Applied Physics, vol. 53, pp. 3813-3818, 1982.

[8] D. Vincenzi, A. Busato, M. Stefancich, and G. Martinelli, "Concentrating PV system based on spectral separation of solar radiation," Physica Status Solidi (a), vol. 206, no. 2, pp. 375-378, 2009.

[9] J. Palm, V. Probst, and F. H. Karg, "Second generation CIS solar modules," Solar Energy, vol. 77, no. 6, pp. 757-765, 2004.

[10] M. Fuentes, G. Nofuentes, J. Aguilera, D. L. Talavera, and M. Castro, "Application and validation of algebraic methods to predict the behavior of crystalline silicon PV modules in Mediterranean climates," Solar Energy, vol. 81, no. 11, pp. 1396-1408, 2007.

[11] R. Levy, "Solar energy conversion can be small-scale and low-tech," Physics Today, vol. 60, pp. 12-14, 2007.

[12] W. Shockley and H. J. Queisser, "Detailed balance limit of efficiency of P-N junction solar cells," Journal of Applied Physics, vol. 32, no. 3, pp. 510-519, 1961.

[13] P. Singh and N. M. Ravindra, "Temperature dependence of solar cell performance-an analysis," Solar Energy Materials and Solar Cells, vol. 101, pp. 36-45, 2012.
[14] A. Q. Malik and M. F. Haji Metali, "Performance of single crystal silicon photovoltaic module in Bruneian climate," International Journal of Applied Science and Engineering, vol. 8, pp. 179-188, 2010.

[15] H. G. Teo, P. S. Lee, and M. N. Hawlader, "An active cooling system for photovoltaic modules," Applied Energy, vol. 90, no. 1, pp. 309-315, 2012.

[16] S. Mekhilef, R. Saidur, and M. Kamalisarvestani, "Effect of dust, humidity and air velocity on efficiency of photovoltaic cells," Renewable and Sustainable Energy Reviews, vol. 16, pp. 2920-2925, 2012.

[17] A. Muzaffar, "Performance enhancement of PV cells through micro channel cooling," in WEENTECH Proceedings in Energy: Global Conference on Energy and Sustainable Development. Coventry: World Energy and Environment Technology Ltd., pp. 211-217, 2015.

[18] Satori. E, "Convection coefficient equations for forced air flow over flat surfaces," Solar Energy, vol. 80, no. 9, pp. 1063-1071, 2006.

[19] A. Yunus, Heat Transfer, A practical approach, p. 372, 2nd edition, 2002. 

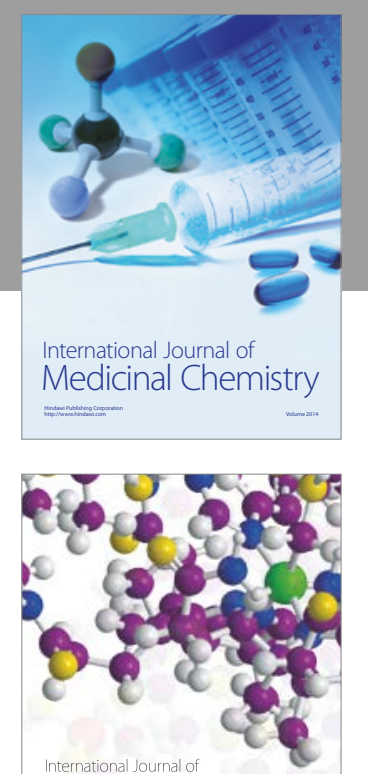

Carbohydrate Chemistry

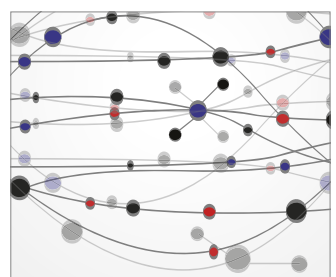

The Scientific World Journal
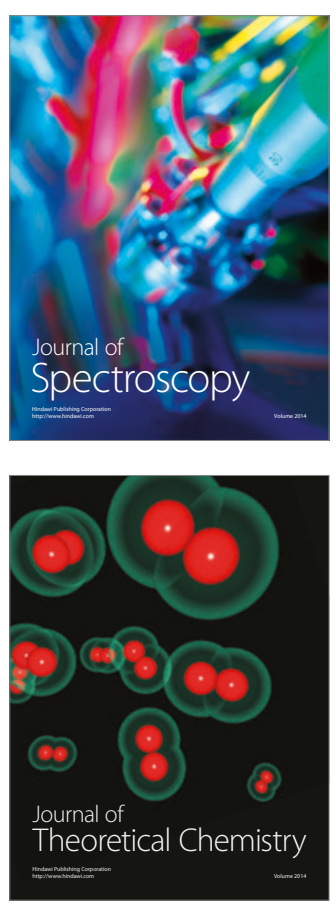
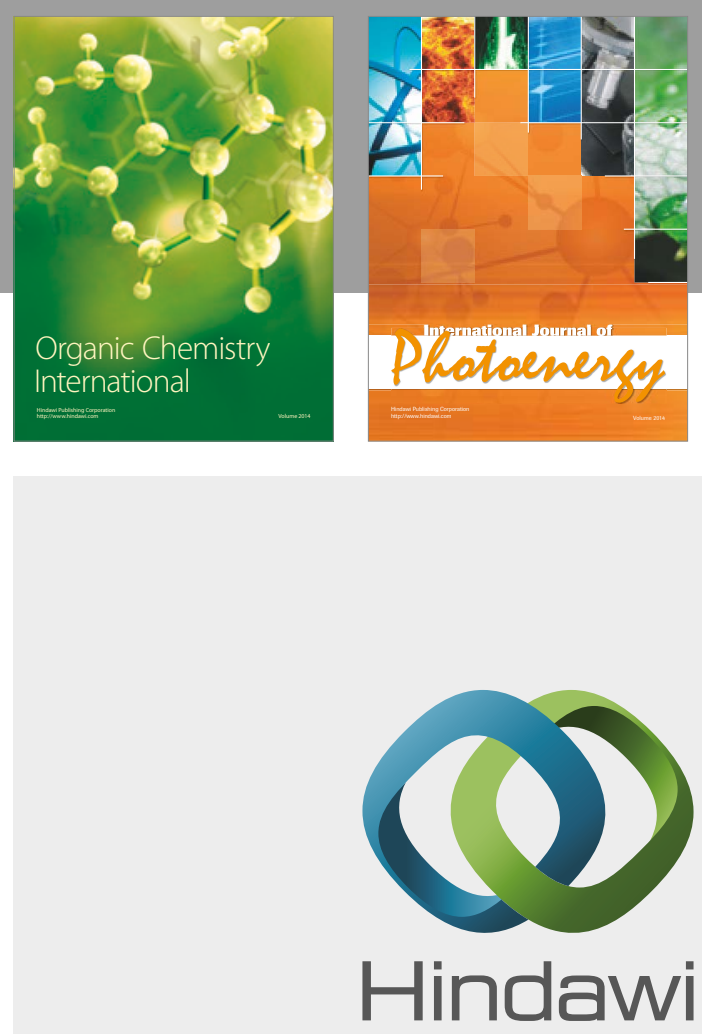

Submit your manuscripts at

https://www.hindawi.com

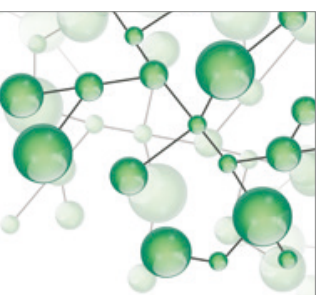

International Journal of

Inorganic Chemistry

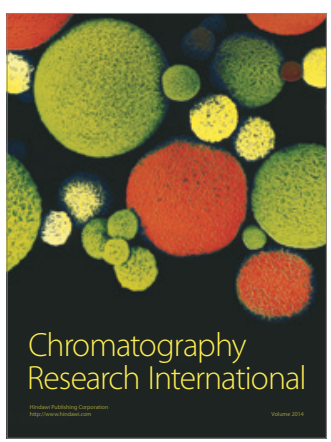

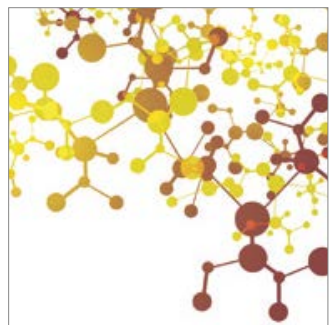

Applied Chemistry
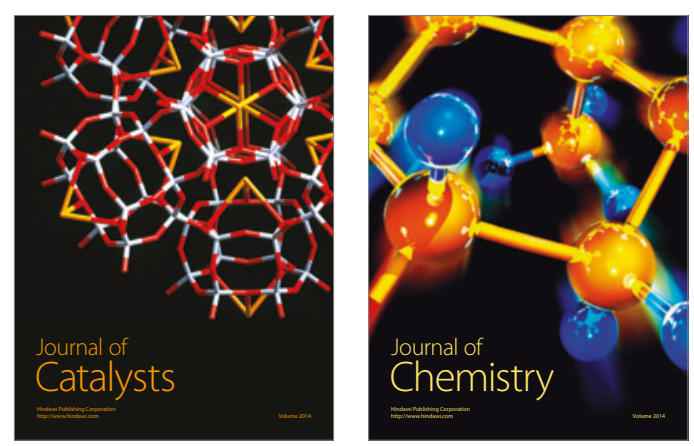
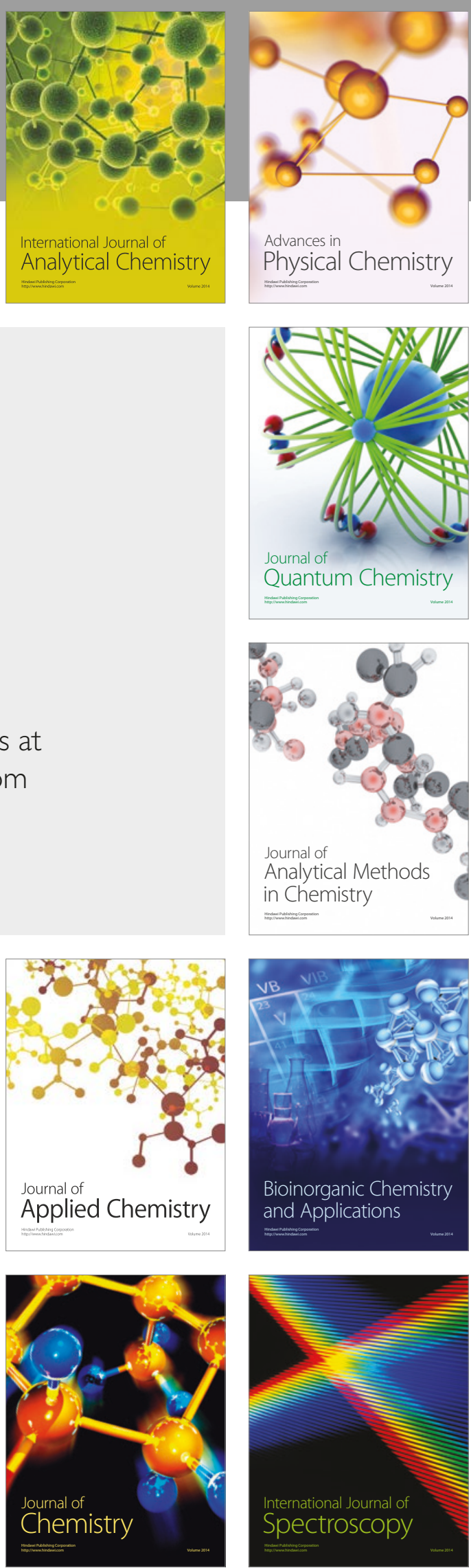